\title{
AN EXPLORATIVE STUDY REGARDING THE RELATIONS BETWEEN DARK TRIAD AND HEXACO MODEL OF PERSONALITY
}

\author{
Dan Florin Stănescu, \& Marius Constantin Romașcanu \\ Communication Department, National University of Political Studies and Public Administration, \\ (Romania)
}

\begin{abstract}
Despite their diverse origins, the personalities composing this Dark Triad share several features. To varying degrees, all three entail a socially malevolent character with behavior tendencies toward self-promotion, emotional coldness, duplicity, and aggressiveness (Paulhus \& Williams, 2002). Subclinical narcissism, Machiavellianism, and psychopathy are referred to as the Dark Triad due to their socially undesirable nature, similar phenotypical behaviors (e.g., manipulation), positive intercorrelations of their scales, and conceptual similarities (e.g., ego-centricity) (Rauthmann, 2012). A narcissistic person is described in terms of a high vanity, constantly seeking attention and admiration, with a sense of superiority or authority. Most often he or she manifests manipulative and exhibitionist behaviors. Machiavellianism is a tendency to be cynical, pragmatic, emotionally detached in interpersonal relations but, at the same time a good organizer and having long-term strategically thinking. Psychopathy presents as cardinal features: impulsiveness, emotional detachment, manipulative antisocial behavior. In the current study 126 participants (24 males and 102 females), ages ranged between 18 and 26 years old $(M=19.30, S D=1.11)$, were invited to fill in the following measures: MACH IV (Christie \& Geis, 1970), Narcissistic Personality Inventory NPI-16 (Ames, Rose \& Anderson, 2006), Self-Report Psychopathy scale - version III (Paulhus, Neumann, \& Hare, 2009) and HEXACO-PI-R (Lee \& Ashton, 2018). Results showed significant negative correlations between psychoticism and four of the six HEXACO factors, namely Honesty-Humility, Emotionality, Agreeableness, and Conscientiousness. Similarly, narcissism is negatively related to Honesty-Humility and Agreeableness, and positively with Extraversion. Machiavellianism showed a positive correlation with Honesty-Humility, Agreeableness, and Conscientiousness. Findings of the current study should be extended in more diverse samples (e.g., better female-male ratio) and also including measures for the Light Triad of personality, thus providing new insights into the positive, growth-oriented personality traits.
\end{abstract}

Keywords: Dark triad, Machiavellianism, narcissism, psychopathy, HEXACO.

\section{Introduction}

Despite their diverse origins, the personalities composing this Dark Triad share a number of features. To varying degrees, all three entail a socially malevolent character with behavior tendencies toward self-promotion, emotional coldness, duplicity, and aggressiveness (Paulhus \& Williams, 2002). Subclinical narcissism, Machiavellianism, and psychopathy are referred to as the Dark Triad due to their socially undesirable nature, similar phenotypical behaviors (e.g., manipulation), positive intercorrelations of their scales, and conceptual similarities (e.g., ego-centricity) (Rauthmann, 2012).

Psychopathy is the tendency to impulsive thrill-seeking, cold affect, manipulation, and antisocial behaviors (Williams, Nathanson, \& Paulhus, 2003), often falling into a primary factor (characterized by callous affect, affective shallowness, lack of empathy and remorse, superficial charm, and interpersonal manipulation) and a secondary factor (expressed through erratic lifestyles and anti-social behaviors, social deviance, low socialization, impulsivity, irresponsibility, aggression, sensation seeking, delinquency; Hare, 2003). Psychopathy is now recognized as a subclinical variable, exhibiting meaningful variation within "normal" populations (Hare, 1991). Psychopathy is also described by cold and rigid affectivity, a superficial interaction style, manipulative in interpersonal relations (Kring \& Bachorowski, 1999).

Machiavellianism is the tendency to cynical, misanthropic, cold, pragmatic, and immoral beliefs; detached affect; pursuit of self-beneficial goals (e.g., power, money); strategic long-term planning; and manipulation tactics (Christie \& Geis, 1970; Rauthmann \& Will, 2011). Machiavellianism 
is also characterized by the manipulation and exploitation of others, cunning, cold affect, and a lack of sincerity or ethical concern (Christie \& Geis, 1970).

High Mach scorers exhibit manipulative behaviours towards others in order to promote their own interests and are found to be emotionally detached in their interactions with others, with an interpersonal orientation, which is described as cognitive as opposed to emotional, and with little tendency to focus on individual differences (Christie \& Geis, 1970). They tend to exhibit a cool and detached attitude, an opportunist approach to norms, regulations and social values. They are able to make use of other people in order to fulfill their own wishes, and often disappoint others (Mudrack \& Mason, 1995). Hunter, Boster și Gerbing (1982, as cited in Reimers, 2004) mentioned four essential components extracted from factorial analysis: flattery, honesty rejection, rejection of the belief that humans are moral, and the conviction that they are corrupt and unreliable.

Strong personalities, Machiavellians are distinguished by the desire to assert themselves, understand what motivates those around them and use this information to their advantage, use personal charm to seduce and conquer, quickly become the leaders of the group they belong to, they rigorously plan every move, they never reveal their own intentions, for them reputation matters a lot, people's good opinion of them being essential in their attempts to manipulate them in order to achieve their goals (Austin, Farrelly, Black, \& Moore, 2007).

Related to psychopathy and Machiavellianism, narcissism represents an exaggeration of self-worth and importance, superiority over others (i.e., grandiosity), and attention-seeking (Raskin \& Terry, 1988). Put simply, narcissism is an “excessive love for one's self” (Vernon et al., 2008, p.445), is the tendency to harbor grandiose and inflated self-views while devaluing others (Morf \& Rhodewalt, 2001).

According to Raskin and Hall (1979), narcissism defines the personality of individuals who manifest facets of grandeur, domination, and superiority. The need to amaze, to be in the center of attention, and to be always appreciated are behaviors that the narcissistic personality manifests to mask the discrepancy between his two identities.

Narcissists are shown to exhibit extreme vanity; attention and admiration seeking; feelings of superiority, authority, and entitlement; exhibitionism and bragging; and manipulation (Raskin \& Terry, 1988). They have a high need of achievement and a low one for affiliation. That is why they easily accept challenges, they show a high degree of competitiveness (Raskin \& Terry, 1988). Narcissists are interested in success, power, beauty and glamour. They live as they are on a stage showing off and asking for others attention and admiration. They might be perceived as being arrogant, dominant and even hostile (Rosenthal \& Pittinsky, 2006).

Moving further, the personality was best described using the well-known Five-Factor Model (FFM) of personality (Costa \& McCrae, 1992; Goldberg, 1990). The aspects of this six-factor model include Honesty-Humility, Emotionality, Extraversion, Agreeableness, Conscientiousness, and Openness to Experience (Ashton \& Lee, 2007).

On one hand, people with high scores on the Honesty-Humility scale avoid manipulating others for personal gain, feel no temptation to break rules, and feel no special entitlement to elevated social status. On the other hand, persons with low scores will flatter others to get what they want, are inclined to break rules for personal profit, are motivated by material gain, and feel a strong sense of self-importance (Ashton \& Lee, 2007).

Persons with high scores on the Emotionality scale experience fear of physical dangers, experience anxiety in response to life's stresses, feel a need for emotional support from others and feel empathy and sentimental attachments with others. Conversely, persons with low scores are not deterred by the prospect of physical harm, feel little worry even in stressful situations, and feel emotionally detached from others (Ashton \& Lee, 2007).

Regarding the Extraversion scale, high scores describe people that feel positively about themselves, feel confident when leading or addressing groups of people, enjoy social gatherings and interactions, and experience positive feelings of enthusiasm and energy. Conversely, persons with low scores feel awkward when they are the center of social attention, are indifferent to social activities, and feel less lively and optimistic than others do (Ashton \& Lee, 2007).

Additionally, persons with high scores on the Agreeableness scale forgive the wrongs that they suffered, are willing to compromise and cooperate with others, and can easily control their temper. Conversely, persons with low scores hold grudges against those who have harmed them, are rather critical of others' shortcomings, are stubborn in defending their point of view, and feel anger readily in response to mistreatment (Ashton \& Lee, 2007).

Furthermore, persons with high scores on the Conscientiousness scale work in a disciplined way toward their goals, strive for accuracy and perfection in their tasks and deliberate carefully when making decisions. Conversely, persons with low scores tend to be unconcerned with orderly surroundings or 
schedules, avoid difficult tasks or challenging goals, are satisfied with work that contains some errors, and make decisions on impulse or with little reflection (Ashton \& Lee, 2007).

On the last scale of the model, Openness to Experience, people with high scores are inquisitive about various domains of knowledge, use their imagination freely in everyday life, and take an interest in unusual ideas or people. Conversely, persons with low scores are rather unimpressed by most works of art, feel little intellectual curiosity, avoid creative pursuits, and feel little attraction toward ideas that may seem radical or unconventional (Ashton \& Lee, 2007).

In view of the above discussion, the following research question is proposed: What relations can be identified between the Dark Triad and HEXACO model of personality?

\section{Methods}

\subsection{Participants}

One hundred and twenty-six employees (24 men, 102 women), aged 18-26 years $(\mathrm{M}=19.30$; $\mathrm{AS}=1.11$ ) coming from both bachelor and master degree were invited to participate in the study. Participants were given the complete packets, including informed consent and measures to complete.

\subsection{Measures}

Self-reported data collection technique was used. All participants were ensured about the confidentiality of the data and that it would be only used for research purpose. Dark Triad was measured using the NPI (Raskin \& Hall, 1979), the Self-Report Psychopathy Scale-III (Paulhus, Neumann, \& Hare, 2009), and the MACH-IV (Christie \& Geis, 1970).

Subclinical narcissism was assessed with the 40-item Narcissistic Personality Inventory (Raskin \& Hall, 1979) which assesses four distinct factors: exploitativeness/entitlement, leadership/authority, superiority/arrogance, and self-absorption/self-admiration. For each item, participants have to choose one of two statements (forced choice) they felt applied to them more. One of the two statements reflected a narcissistic attitude (e.g., "I have a natural talent for influencing people."), whereas the other one did not (e.g., "I am not good at influencing people."). Kansi (2003) reported a good alpha of 0.80 .

The 31-item Self-Report Psychopathy Scale-III (Paulhus, Neumann, \& Hare, 2009) was used to assess nonclinical psychopathy. Participants rated how much they agreed $(1=$ strongly disagree, 5 = strongly agree) with statements such as, "I purposely flatter people to get them on my side" (IPM); "I never feel guilty for hurting others" (CA); "I've often done something dangerous just for the thrill of it" (ELS); and "I have tricked someone into giving me money" (CT). These items reflect psychopathic characteristics modeled in four dimensions: interpersonal manipulation (IPM), callous affect (CA), erratic life style (ELS), and criminal tendencies (CT). Good alpha were reported both for the total score (.81) and for the scales (between .74 and .82).

Machiavellianism was measured with the 20-item MACH-IV (Christie \& Geis, 1970). Those items cover the use of deceit in interpersonal relationships, and a cynical attitude to human nature. Participants respond by indicating the extent to which they agree with each statement on a 5-point Likert scale. In this questionnaire, higher scores represent higher levels of Machiavellianism, as defined by manipulative interpersonal strategies and a skeptical view of others. An example item is 'The best way to handle people is to tell them what they want to hear.' Corral and Calvete (2000) reported an alpha of .70.

The HEXACO model of personality was assessed with the HEXACO-PI-R (HEXACO Personality Instrument Revised; Ashton, \& Lee, 2009). This model is an alternative to the well-known Big Five model, having a common structure with it. The HEXACO model contains the factors Honesty-Humility, Affectivity (E - Emotionality), Extraversion (X - Extraversion), Ability (A - Agreeableness), Conscientiousness (C - Conscientiousness) and Openness to Experience to Experience). Response options for each item range from 1 ("strongly disagree") to 5 ("strongly agree"). The authors reported adequate internal consistency (apha between .77 to .80 ).

\section{Results}

After collection, the data were analysed using SPSS 26.0 version software. Table 1 shows Honesty-humility to be negatively correlated with Narcissism $(r=-.350, p<.01)$ and subclinical psychopathy $(\mathrm{r}=-.505, \mathrm{p}<.01)$, and positively correlated with Machiavellianism $(\mathrm{r}=.288, \mathrm{p}<.01)$, whereas, Emotionality negatively correlated only with subclinical psychopathy $(\mathrm{r}=-.240, \mathrm{p}<.01)$ and Extraversion only with Narcissism $(\mathrm{r}=.416, \mathrm{p}<.01)$. 
Table 1. Bivariate correlations between Dark Triad components and Hexaco model of personality (a).

\begin{tabular}{llccc}
\hline & & Honesty-humility & Emotionality & \multicolumn{2}{c}{ Extraversion } \\
\hline Narcissism & Pearson Correl. & $-.350^{* *}$ & -.137 & $.416^{* *}$ \\
& Sig. (2-tailed) & .000 & .126 & .000 \\
Machiavellianism & Pearson Correl. & $.288^{* *}$ & .167 & .139 \\
& Sig. (2-tailed) & .001 & .061 & .121 \\
& Pearson Correl. & $-.505^{* *}$ & $-.240^{* *}$ & -.099 \\
& Sig. (2-tailed) & .000 & .007 & .268 \\
\hline
\end{tabular}

Furthermore, the correlations run to test the relations between Dark Triad components and the rest of HEXACO scales (table 2), showed significant negative correlations between Agreeableness and Narcissism $(\mathrm{r}=-.242, \mathrm{p}<.01)$, respectively subclinical psychopathy $(\mathrm{r}=-.315, \mathrm{p}<.01)$, and positively correlation with Machiavellianism $(\mathrm{r}=.269, \mathrm{p}<.01)$. The same significant results were also identified for the correlations between Conscientiousness and Machiavellianism $(\mathrm{r}=.252, \mathrm{p}<.01)$, and between Conscientiousness and subclinical psychopathy $(r=-.315, \mathrm{p}<.01)$.

Table 2. Bivariate correlations between Dark Triad components and Hexaco model of personality (b).

\begin{tabular}{llccc}
\hline & & Agreeableness & Conscientiousness & Openness to experience \\
\hline Narcissism & Pearson Correl. & $-.242^{* *}$ & .030 & .025 \\
& Sig. (2-tailed) & .006 & .739 & .785 \\
Machiavellianism & Pearson Correl. & $.269^{* *}$ & $.252^{* *}$ & -.027 \\
& Sig. (2-tailed) & .002 & .004 & .767 \\
Psychopathy & Pearson Correl. & $-.315^{* *}$ & $-.315^{* *}$ & .030 \\
& Sig. (2-tailed) & .000 & .000 & .741 \\
\hline
\end{tabular}

\section{Conclusions}

The present study examined the relations between the broad HEXACO model of personality and the Dark Triad constructs. Results were consistent with the findings of Lee and Ashton (2005) who found that Narcissism was positively related to Extraversion. Psychopathy was inversely related to Emotionality, Conscientiousness, and Agreeableness (Lee \& Ashton, 2005). Moreover, our results are mirroring previous research who noted that the Honesty-Humility facets are also empirically related to the individual Dark Triad subscales, with meta-analytic correlations in the -.09 to -.56 range (averaging -.36) (Muris et al., 2017).

One of the main weaknesses of this study was the use of a cross-sectional design, which does not allow for an assessment of the cause-effect relation. Also, the questionnaires were self-reported, which may result in common method bias. Moreover, there are some limitations that future studies should address. First, neither subfacets nor different "forms" of each Dark Triad trait were investigated (Jonason, Kavanagh, Webster, \& Fitzgerald, 2011). For example, grandiose versus vulnerable narcissism (Miller et al., 2011) and primary versus secondary psychopathy (Hare, 2003) can be distinguished. Also, Machiavellianism likely has subfacets (tactics, morality, and views) despite being often unidimensionally conceptualized (Rauthmann \& Will, 2011).

To sum up, findings of the current study should be extended in more diverse samples (e.g., better female-male ratio, different age ranges etc.), with different or more complex Dark Triad measures, or even including a comparison with Light Triad measures, and with different research designs (e.g., mixed methods).

\section{References}

Ames, D.R., Rose, P., \& Anderson, C.P. (2006). The NPI-16 as a short measure of narcissism. Journal of Research in Personality, 40, 440-450.

Ashton, M.C., \& Lee, K. (2007). Empirical, theoretical, and practical advantages of the HEXACO model of personality structure. Personality and Social Psychology Review, 11, 150-166.

Ashton, M.C., \& Lee, K. (2009). The HEXACO-60: A short measure of the major dimensions of personality. Journal of Personality Assessment, 91, 340-345. 
Austin, E.J., Farrelly, D., Black, C., \& Moore, H. (2007). Emotional intelligence, Machiavellianism and emotional manipulation: Does EI have a dark side?. Personality and Individual Differences, 43(1), 179-189.

Christie, R., \& Geis, F. (1970). Studies in Machiavellianism. New York: Academic Press.

Corral, S., \& Calvete, E. (2000). Machiavellianism: Dimensionality of the Mach IV and its Relation to Self-Monitoring in a Spanish Sample. The Spanish Journal of Psychology, 3(1), 3-13.

Hare, R.D. (1991). The Hare Psychopathy Checklist-Revised. Toronto: Multi-Health Systems.

Hare, R.D. (2003). The Hare psychopathy checklist-revised. (PCL-R; 2nd ed.). Toronto, Canada: Multi-Health Systems.

Jonason, P.K., Kavanagh, P.S., Webster, G., \& Fitzgerald, D., (2011). Comparing the Measured and Latent Dark Triad: Are Three Measures Better than One? Journal of Methods and Measurement in the Social Sciences, 2(1), 28-44.

Kansi, J. (2003). The Narcissistic Personality Inventory: Applicability in a Swedish population sample. Scandinavian Journal of Psychology, 44(5), 441-448.

Kring, A., \& Bachorowski, J. (1999). Emotions and Psychopathology, Vanderbilt University, Nashville, USA.

Lee, K., \& Ashton, M. C. (2005). Psychopathy, Machiavellianism, and Narcissism in the Five-Factor Model and the HEXACO model of personality structure. Personality and Individual Differences, 38, 1571-1582. doi: 10.1016/j.paid.2004.09.016

Lee, K., \& Ashton, M.C. (2018). Psychometric properties of the HEXACO-100. Assessment, 25(5), 543-556.

Miller, J.D., Hoffman, B.J., Gaughan, E.T., Gentile, B., Maples, J., \& Campbell, W. K. (2011). Grandiose and vulnerable narcissism: A nomological network analysis. Journal of Personality, 79, 1013-1042.

Morf, C.C., \& Rhodewalt, F. (2001). Unraveling the paradoxes of Narcissism: A dynamic self-regulatory processing model. Psychological Inquiry, 12, 177-196.

Mudrack, P.E., \& Mason, E.S. (2013). Ethical judgments: What do we know, where do we go? Journal of Business Ethics, 115(3), 575-597.

Muris, P., Merckelbach, H., Otgaar, H., \& Meijer, E. (2017). The malevolent side of human nature: A meta-analysis and critical review of the literature on the Dark Triad (narcissism, Machiavellianism, and psychopathy). Perspectives on Psychological Science, 12(2), 183-204.

Paulhus, D.L., \& Williams, K.M. (2002). The Dark Triad of personality: Narcissism, Machiavellianism and psychopathy. Journal of Research in Personality, 36(6), 556-563. https://doi.org/10.1016/S0092-6566(02)00505-6

Paulhus, D.L., Neumann, C.S., \& Hare, R.D. (2009). Manual for the self-report psychopathy scale. Toronto: Multi-Health Systems.

Raskin, R., \& Terry, H. (1988). A principal-components analysis of the narcissistic personality inventory and further evidence of its construct validity. Journal of Personality and Social Psychology, 54, 890-902.

Raskin, R.N., \& Hall, C.S. (1979). A narcissistic personality inventory. Psychological Reports, 45(2), 590. https://doi.org/10.2466/pr0.1979.45.2.590

Rauthmann, J.F. (2012). The Dark Triad and interpersonal perception: Similarities and differences in the social consequences of narcissism, Machiavellianism, and psychopathy. Social Psychological and Personality Science, 3(4), 487-496. https://doi.org/10.1177/1948550611427608

Rauthmann, J.F., \& Will, T. (2011). Proposing a multidimensional Machiavellianism conceptualization. Social Behavior and Personality, 39, 391-404.

Reimers, J. (2004). Assessing Political Leadership - A Review of Christie and Geis ' (1970) Mach IV Measure of Machiavellianism, University of Nebraska - Lincoln.

Rosenthal, A., \& Pittinsky, T.L. (2006). Narcissistic Leadership. The Leadership Quarterly, 17, 617-633.

Vernon, P.A., Villani, V.C., Vickers, L.C., \& Harris, J.A. (2008). A behavioral genetic investigation of the dark triad and the Big 5. Personality and Individual Differences, 44, 445-452.

Williams, K.M., Nathanson, C., \& Paulhus, D.L. (2003). Structure and validity of the self-report psychopathy scale-III in normal populations. Presentation at the 11th annual convention of the American Psychological Association, Toronto, Canada. 